\title{
ADSORPSI LOGAM Pb dan Cu DARI PELUMAS BEKAS MENGGUNAKAN BLENDING SELULOSA ASETAT-KITOSAN
}

\section{[Adsorption of $\mathrm{Pb}$ and $\mathrm{Cu}$ Metals from Used Lubricants Using Blending Cellulose Acetat-Chitosan]}

\author{
Fitra Langgeng Mangesti ${ }^{1}{ }^{\star}$, Husain Sosidi ${ }^{1}$, Prismawiryanti $^{1}$, Syamsuddin ${ }^{1}$ \\ 1) Jurusan Kimia, Fakultas MIPA, Universitas Tadulako, Palu \\ Jl. Soekarno Hatta Km.9, Kampus Bumi Tadulako Tondo Palu, Telp. 0451- 422611 \\ *)Coresponding author: vtra.smile@gmail.com (082259696633)
}

Diterima 26 Juni 2019, Disetujui 2 Agustus 2019

\begin{abstract}
Research on adsorption of $\mathrm{Pb}$ and $\mathrm{Cu}$ metals from used lubricants has been carried out using cellulose acetate-chitosan blending which aims to determine the best ratio and $\mathrm{pH}$ between cellulose acetate and chitosan which can adsorb metal $\mathrm{Pb}$ and $\mathrm{Cu}$ from used lubricants. Cellulose acetate was synthesized through the acetylation method using cellulose extracted from palm fiber coir. The obtained cellulose acetate is brown fine powder with a yield of $62 \%$ and has a water content of $20 \%$. Cellulose acetate was characterized using FT-IR while adsorption of $\mathrm{Pb}$ and $\mathrm{Cu}$ metals from used lubricants using AAS. The results of FT-IR analysis showed the formation of cellulose acetate with an absorption band of $1637.56 \mathrm{~cm}^{-1}$ which proved the presence of carbonyl groups $(C=O)$. The AAS results showed that the best ratio and $\mathrm{pH}$ to absorb $\mathrm{Pb}$ and $\mathrm{Cu}$ metals in used lubricants is $3: 1$ with $\mathrm{pH} 6$.
\end{abstract}

Keywords : palm oil coir, acetate cellulose, chitosan, used lubricants

\begin{abstract}
ABSTRAK
Telah dilakukan penelitian tentang adsorpsi logam $\mathrm{Pb}$ dan $\mathrm{Cu}$ dari pelumas bekas menggunakan blending selulosa asetat-kitosan yang bertujuan untuk mengetahui rasio dan $\mathrm{pH}$ terbaik antara selulosa asetat terhadap kitosan yang dapat mengadsorpsi logam $\mathrm{Pb}$ dan $\mathrm{Cu}$ pada pelumas bekas. Selulosa asetat disintesis melalui metode asetilasi menggunakan selulosa sabut kelapa sawit. Selulosa asetat yang dihasilkan memiliki bentuk berupa serbuk halus berwarna coklat dengan rendemen sebesar $62 \%$ dan memiliki kandungan air sebesar $20 \%$. Selulosa asetat dikarakterisasi menggunakan FT-IR sedangkan adsorpsi logam $\mathrm{Pb}$ dan $\mathrm{Cu}$ dari pelumas bekas menggunakan AAS. Hasil analisis FT-IR menunjukkan terbentuknya selulosa asetat dengan pita serapan $1637,56 \mathrm{~cm}^{-1}$ yang membuktikan adanya gugus karbonil $(\mathrm{C}=\mathrm{O})$. Hasil AAS menunjukkan bahwa perbandingan rasio dan $\mathrm{pH}$ tebaik untuk menyerap logam $\mathrm{Pb}$ dan $\mathrm{Cu}$ pada pelumas bekas ialah 3:1 dengan $\mathrm{pH} 6$.
\end{abstract}

Kata Kunci : sabut kelapa sawit, selulosa asetat, kitosan, pelumas bekas 


\section{LATAR BELAKANG}

Pelumas mesin adalah cairan yang berfungsi untuk melumasi berbagai komponen mesin yang saling bergesekan sehingga mesin tidak mudah aus atau berkarat. Namun, dalam jangka waktu yang lama fungsi pelumas akan mengalami perubahan yang disebabkan oleh suhu yang tinggi dan kotoran pada bagian mesin yang terlepas. Sehingga, pelumas bekas umumnya mengandung logam-logam berat yang bersifat karsinogenik, kotoran abu, aspal dan pengotor lainnya yang bersifat asam, korosif dan deposit. Logam-logam berat seperti timbal $(\mathrm{Pb})$, besi $(\mathrm{Fe})$, tembaga (Cu) merupakan logam yang terkandung dalam minyak pelumas (Hasyim, 2016). Menurut Jodeh et al. (2015) hasil analisis konsentrasi logam timbal $(\mathrm{Pb})$ pada pelumas baru dan bekas terjadi peningkatan dari 0.3954 ppm menjadi 0.5672 ppm. Pada penelitian yang dilakukan oleh Abdel-jabbar et al. (2010) diperoleh kandungan logam $\mathrm{Cu}$ pada pelumas bekas sebesar $7 \mathrm{ppm}$.

Menurut BPS (2013) penggunaan minyak pelumas dalam Industri besar mencapai 111.614.288 Liter pada tahun 2013. Sedangkan, menurut pemantauan rincian impor dari Kementrian Perindustrian, di Indonesia jumlah impor bahan bakar dan pelumas yang belum diolah mengalami peningkatan sebesar $11,00 \%$ dan olahannya sebesar $62,84 \%$ pada tahun 2010. Semakin banyak konsumsi minyak pelumas maka semakin banyak pula limbah minyak pelumas bekas yang dihasilkan. Pengurangan pencemar pada limbah oli penting dilakukan agar oli bekas dapat dimanfaatkan kembali sehingga mengurangi penggunaan minyak bumi.

Kontaminan yang terkandung dalam limbah pelumas bekas yang dihasilkan dari perindustrian, pertambangan dan perbengkelan dapat membahayakan ekosistem baik mencemari air maupun tanah. Apabila limbah ini terbuang ke tanah dan partikel-partikel tanah akan menyerap, maka kemampuan tanah untuk menyerap air akan menurun sehingga menyebabkan terjadinya aerasi tanah. Pelumas termasuk dalam golongan limbah B3, yaitu suatu limbah bahan berbahaya dan beracun. Apabila limbah pelumas bekas tidak dikelola maka akan menyebabkan pencemaran pada udara, tanah dan air sehingga menyebabkan kontaminasi (P3KNLH, 2008 dalam Azteria dan Efendi, 2017).

Dari permasalahan tersebut, untuk mengolah pelumas bekas dapat dilakukan dengan metode adsorpsi dan penjernihan. Pada proses adsorpsi dapat menjerap logam-logam berat yang terkandung di dalamnya. Sehingga, pelumas bekas dapat digunakan kembali sebagai bahan baku (base oil) dalam pembuatan oli (Prasaji, 2013). Telah digunakan metode untuk mengelola limbah pelumas bekas ini. Seperti yang telah dilakukan oleh Pratiwi (2013) menggunakan metode acid clay dalam mengolah minyak pelumas 
bekas. Adsorben yang digunakan ialah kaolin yang diaktivasi dengan asam sulfat. Penurunan kadar $\mathrm{Pb}$ yang diperoleh sebesar $56,71 \%$. Penelitian tentang daur ulang limbah pelumas bekas juga dilakukan oleh Muckti (2012) bahwa adsorbsi logam $\mathrm{Pb}$ pada pelumas bekas dapat dilakukan menggunakan adsorben batu bara dan arang aktif. Dimana penurunan kadar $\mathrm{Pb}$ pada pelumas bekas diperoleh dari 12,81 ppm menjadi 0,09 ppm. Pemisahan oli bekas dilakukan pula oleh Dahlan et al. (2014) ia menggunakan kolom filtrasi dan membran keramik berbahan baku zeolit dan lempung sehingga mengasilkan penurunan kadar $\mathrm{Cu}$. Pada membran zeolit 40\% kandungan Cu turun dari 5,5 ppm menjadi 0,009 ppm.

Penggunaan adsorben saat ini telah banyak dikembangkan dengan berbagai jenis selulosa. Selulosa merupakan salah satu adsorben karena memiliki gugus karboksil dan hidroksil yang dapat mengikat ion logam. Gugus - $\mathrm{OH}$ pada selulosa menyebabkan adsorben bersifat polar. Sehingga, selulosa mampu menjerap zat yang bersifat lebih polar daripada zat yang kurang polar (Herwanto, 2006). Selulosa banyak terkandung dalam sabut kelapa sawit yaitu sebesar 59 \%. Sabut kelapa sawit yang telah diaktivasi mampu menyerap besi dan seng dari konsentrasi awal masingmasing yaitu sebesar 4,919 ppm dan seng 0,031 ppm menjadi tidak terdeteksi atau nol (Muthia, 1998). Pada penelitian Baroroh et al. (2016) selulosa sebanyak
$10 \mathrm{~g} / \mathrm{L}$ dapat mengadsorpsi $\mathrm{Ni}$ pada limbah cair elektroplating sebanyak $69,66 \%$. Sehingga selulosa perlu dicampur atau diblending dengan adsorben lain agar lebih efektif dalam menyerap logam berat.

Selulosa pada umunya digunakan sebagai adsorben dalam bnetuk senyawa selulosa asetat. Selulosa asetat merupakan ester asam organik dari senyawa selulosa dan selulosa asetat diperoleh dari proses asetilasi selulosa. Selulosa asetat banyak digunakan sebagai bahan dasar pembuatan membran yang dimanfaatkan dalam teknik pemisahan logam-logam berat. Pada penelitian yang dilakukan oleh Thaiyibah et al. (2016) menunjukkan bahwa adanya interaksi antara ion $\mathrm{Cu}^{2+}$ dengan membran campuran selulosa asetat dan PVC terjadi penurunan intensitas serapan sebelum dan sesudah dop yakni dari $78.56 \%$ menjadi $66.86 \%$.

Kitosan juga dapat dimodifikasi dengan penambahan adsorben lain seperti silika, zeolit, dan arang aktif. Adanya gugus hidroksil dan amina menyebabkan kitosan mudah dimodifikasi secara kimia. Kitosan melalui proses impregnasi menggunakan gugus pengaktif menghasilkan kitosan termodifikasi dengan daya adsorpsi yang lebih baik terhadap logam-logam berat. Sifat kebasaan dari gugus aktif kitosan memainkan peran penting dalam proses pemodifikasi (Liu, 2007). Kitosan dalam banyak digunakan sebagai adsorben atau 
pengikat ion (Roberts, 1992). Kitosan berperan dalam mengadsorpsi kation karena pada kitosan terdapat gugus amino dan hidroksil yang menyebabkan kitosan menjadi reaktif yang disebabkan adanya sifat polielektrolit yang dimiliki (Marganof, 2007 dalam Permanasari et al., 2010).

Adsorpsi merupakan perpindahan massa adsorbat dari fase gerak (fluida pembawa adsorbat) yang dipengaruhi oleh beberapa faktor yakni sifat fisis dan kimia adsorben. Sifat fisis meliputi luas permukaan, ukuran pori, dan komposisi kimia molekul. Sedangkan, sifat kimia adsorbat meliputi ukuran, kepolaran, dan komposisi kimia molekul. Faktor lainnya seperti konsentrasi adsorbat dalam fase cair, kondisi fase cair $(\mathrm{pH}$ dan suhu), serta kondisi kerja adsorpsi (Rahmawati, 2006). Adsorben harus mempunyai daya ikat yang kuat terhadap zat yang hendak dipisahkan secara fisis atau pun kimia. Luas permukaan yang besar dapat diperoleh dengan cara memperkecil ukuran-ukuran partikel (Lianna et al., 2012). Salah satu jenis adsorben yang dapat digunakan untuk mengadsorpsi pengotor dalam pelumas bekas adalah membran selulosa asetat. Namun, selulosa asetat yang dibutuhkan cukup banyak. Untuk mengefisiensi penggunaan selulosa asetat maka ditambahkan kitosan dengan perbandingan yang sama. Karena, kitosan dan selulosa asetat mampu menjerap logam sehingga dilakukan penelitian mengenai adsorpsi logam pelumas bekas menggunakan selulosa asetat sabut kelapa sawit terhadap kitosan.

\section{METODE PENELITIAN}

\section{Bahan dan Peralatan}

Bahan yang digunakan adalah sabut kelapa sawit, pelumas bekas merk SGO4T 20W-50 SG MA, kitosan produksi Lilita, selulosa mikrokristalin produksi CV. Agung Menara Abadi, $\mathrm{NaCl}, \mathrm{NaOH} 15 \%$, $\mathrm{NaOCl} 6 \%, \mathrm{CH}_{3} \mathrm{COOH}$ glasial, akuades, $\mathrm{Na}_{2} \mathrm{~S}_{2} \mathrm{O}_{5} 3 \%, \mathrm{H}_{2} \mathrm{SO}_{4}$ pekat, $\mathrm{HCl} 6 \mathrm{~N}, \mathrm{HNO}_{3}$ $0,1 \mathrm{~N}$ dan aluminium foil, dan tissu.

Peralatan yang digunakan ini adalah neraca analitik, blender, ayakan 60 mesh, oven, botol semprot, spatula, FTIR, spektrofotometer serapan atom GBC 932 AA dan alat-alat gelas yang umumnya digunakan dalam Laboratorium kimia.

\section{Prosedur Penelitian}

\section{Isolasi selulosa (Ferdiansyah et al., 2015)}

Merendam sabut kelapa sawit yang telah terpisah dari kulitnya selama 2 jam dalam air. Kemudian, menjemur selama 2 hari di bawah sinar matahari. Menghaluskan sabut kelapa sawit dan mengayak menggunakan ayakan 60 mesh. Mengekstraksi sabut kelapa sawit menggunakan larutan $\mathrm{NaOH} 15 \%$ dengan perbandingan $1: 20(\mathrm{~b} / \mathrm{v})$ pada suhu $100^{\circ} \mathrm{C}$ selama 3 jam. Residu yang diperoleh di cuci dengan akuades. Selanjutnya, merendam ekstrak dengan $700 \mathrm{ml}$ akuades yang dicampur dengan 14 g NaCl dan $35 \mathrm{~mL}$ asam asetat $10 \%$. 
Residu kemudian di bleaching $700 \mathrm{~mL} \mathrm{Na}$ metabisulfit $3 \%$ (b/v) dan $700 \mathrm{~mL} \mathrm{NaOCl}$ $6 \%$ selama 3 jam dengan suhu $60^{\circ} \mathrm{C}$. Mencuci tepung selulosa yang diperoleh sampai tidak berbau hipoklorit. Kemudian, keringkan tepung selulosa dalam oven dengan suhu $110^{\circ} \mathrm{C}$ selama 6 jam dan dihitung rendemennya.

Rendemen (\%) $=\frac{\text { Berat } \text { kering }}{\text { Berat } \text { serbuk }} \times 100 \%$

\section{Asetilasi selulosa (Suryani, 2011 dalam Lestari, 2012)}

Menimbang tepung selulosa sebanyak 10 gram. Lalu, menambahkan $24 \mathrm{~mL}$ asam asetat glasial dalam erlenmeyer yang tertutup dan di aduk dengan suhu $40^{\circ} \mathrm{C}$ selama 1 jam. Kemudian, menambahkan $60 \mathrm{~mL}$ asam asetat glasial dan $0,5 \mathrm{~mL} \mathrm{H}_{2} \mathrm{SO}_{4}$ pekat ke dalam larutan dan mengaduknya pada suhu $40^{\circ} \mathrm{C}$ selama 45 menit setelah itu mendinginkan campuran hingga suhu $18^{\circ} \mathrm{C}$. Selanjutnya, menambahkan $27 \mathrm{~mL}$ anhidrida asetat yang dingin hingga suhu $15^{\circ} \mathrm{C}$ dan mengaduknya selama 3 jam menggunakan magnetic stirrer pada suhu kamar. Campuran ditambahkan $30 \mathrm{~mL}$ asam asetat $67 \%(\mathrm{v} / \mathrm{v})$ dengan suhu $40^{\circ} \mathrm{C}$ dan mengaduk selama 15 jam menggunakan magnetic stirrer. Kemudian, menetesi endapan dengan akuades sambil diaduk hingga diperoleh endapan yang berbentuk serbuk. Cuci endapan hingga netral dan menyaringnya. Selanjutnya dikeringkan pada suhu $110^{\circ} \mathrm{C}$ selama 6 jam dan dihitung rendemennya.
Rendemen (\%) $=\frac{\text { Berat } \text { kering }}{\text { Berat selulosa }} \times 100 \%$

\section{Analisis kadar air (Souhoka, 2013)}

Analisis kadar air ini mengacu pada metode AOAC (1995) yakni dengan mengeringan dalam oven cawan petri dengan suhu $105^{\circ} \mathrm{C}$ selama 1 jam. Lalu, mendinginkan dalam desikator selama 30 menit. Mengeringkan sampel sebanyak 1 gr dalam oven pada suhu $105^{\circ} \mathrm{C}$ selama 2 jam dan mendinginkannya dalam desikator selama 30 menit, dilakukan berulang kali kemudian beratnya ditentukan sampai konstan. Penentuan kadar air dapat dihitung menggunakan persamaan berikut.

Kadar air $(\%)=\frac{\text { Berat awal }- \text { berat } \text { kering }}{\text { berat } \text { awal }} \times 100 \%$

\section{Analisis Spektrofotometer FTIR}

Mencampurkan serbuk kering $\mathrm{KBr}$ sebanyak 50 miligram dengan sampel sebanyak 20 miligram, digerus hingga homogen. Campuran dicetak dalam pellet press dengan kompresi hidrolik berkekuatan 2 torr yang terhubung dengan pompa vakum. Pellet $\mathrm{KBr}$ yang telah terbentuk diletakkan pada tempat sampel diantara dua celah yang dilewati berkas sinar inframerah. Spketrum diatur pada bilangan gelombang $4500-400 \mathrm{~cm}^{-1}$ lalu di running, hasil yang diperoleh merupakan spekrum yang kemudian dianalisis gugus fungsinya.

Pembuatan selulosa asetat-kitosan (Modifikasi Metode Lestari, 2012)

Membuat campuran dengan melarutkan selulosa dan kitosan dengan 
masing-masing pelarutnya. Membuat selulosa $3 \%$ ( $\left.3 \mathrm{~g} / 100 \mathrm{~mL} \mathrm{CH} \mathrm{CH}_{3} \mathrm{COOH} 1 \%\right)$ dan kitosan $3 \%\left(3 \mathrm{~g} / 100 \mathrm{~mL} \mathrm{CH} \mathrm{CH}_{3} \mathrm{COOH}\right.$ $1 \%)$. Kemudian, membuat rasio selulosa dan kitosan dengan perbandingan 1:1, 2:1 dan 3:1. Mengaduk masing-masing campuran hingga larut seluruhnya. Tiaptiap campuran variasikan $\mathrm{pH}$-nya menjadi $\mathrm{pH} 5$ dan 6. Kemudian, menguapkan campuran hingga kering dan menyimpannya dalam wadah tertutup dengan suhu kamar.

\section{Adsorpsi logam $\mathrm{Pb}$ dan $\mathrm{Cu}$ dari pelumas bekas (Joseph, 2010 dalam Kusumah, 2013)}

Sampel pelumas bekas sebanyak $200 \mathrm{~mL}$ dalam gelas piala diaduk pada kecepatan 100 rpm ditambahkan $40 \mathrm{~mL}$ $\mathrm{H}_{2} \mathrm{SO}_{4}$ pekat. Campuran diaduk selama 3 jam hingga homogen dan didiamkan selama 48 jam hingga terbentuk 2 lapisan dan lapisan minyak diambil untuk dianalisis. Lapisan minyak yang telah diperoleh dipanaskan pada suhu $120^{\circ} \mathrm{C}$. Lalu, dimasukkan campuran selulosa asetat-kitosan dari masing-masing rasio dan $\mathrm{pH}$ ke dalam pelumas bekas tersebut dengan perbandingan 1:1 $\mathrm{v} / \mathrm{v}$, aduk selama 3 jam, kemudian, diamkan selama 24 jam dan saring.

\section{Analisa logam $\mathrm{Pb}$ dan $\mathrm{Cu}$ dengan metode destruksi kering (Hajrah et al., 2018)}

Analisa ini mengacu pada SNI 013741-2012 (Badan Standarisasi Nasional, 2012). Dengan memasukkan $5 \mathrm{~mL}$ kedalam cawan porselen dan ditanur dengan suhu $450^{\circ} \mathrm{C}$ selama 2 jam. Abu yang telah dingin di tetesi air dan $\mathrm{HNO}_{3}$ pekat sebanyak $0,5 \mathrm{~mL}$ hingga $3 \mathrm{~mL}$. Kemudian abu kembali di tanur pada suhu $450^{\circ} \mathrm{C}$ selama 2 jam hingga diperoleh abu berwarna putih. Abu putih dilarutkan dengan $5 \mathrm{~mL} \mathrm{HCl} 6 \mathrm{~N}$ sambil dipanaskan hingga kering. Lalu, melarutkan kembali dengan $\mathrm{HNO}_{3} \quad 0,1 \mathrm{~N}$ dalam labu ukur 50 $\mathrm{mL}$. Tepatkan volumenya menggunakan akuades. Absorbansi larutan standar dan larutan sampel diukur menggunakan SSA pada panjang gelombang $217 \mathrm{~nm}$ untuk analisa logam $\mathrm{Pb}$ dan panjang gelombang $324,7 \mathrm{~nm}$ untuk analisa logam $\mathrm{Cu}$.

\section{HASIL DAN PEMBAHASAN}

\section{Selulosa asetat hasil sintesis}

Hasil sintesis selulosa asetat dari selulosa sabut kelapa sawit memiliki bentuk berupa serat-serat halus berwarna coklat. Selulosa asetat dibuat melalui proses asetilasi dari selulosa sabut kelapa sawit. Asetilasi selulosa menggunakan larutan anhidrida asetat dan asam sulfat sebagai katalis. Dari 10 gram selulosa sabut kelapa sawit diperoleh selulosa asetat sebanyak 6,2 gram. Sehingga rendemen yang dihasilkan sebesar $62 \%$, yang memiliki kadar air $20 \%$. Rendemen selulosa asetat yang diperoleh lebih tinggi dibandingkan rendemen selulosa asetat dari selulosa pelepah pisang yang dilakukan oleh Apriana et al. (2018) yang memperoleh rendemen sebesar $50 \%$. Hasil rendemen yang diperoleh dalam penelitian Nurhayati dan Rinta (2014) 
bahwa rendemen selulosa asetat dari limbah pengolahan agar sebesar 26,19\% dengan perbandingan selulosa dan asetat anhidrida ialah 1 : 10. Sedangkan, penelitian yang dilakukan oleh Israel et al (2008) memperoleh rendemen selulosa triasetat dari selulosa limbah batang jagung dan batang pisang masing-masing yakni 40,6 \% dan 38,7 \%. Rendemen selulosa asetat dipengaruhi beberapa faktor diantaranya jenis dan kadar air bahan baku yang digunakan, rasio pencampuran antara selulosa dan asam asetat, suhu dan waktu selama proses asetilasi (Bahmid et al., 2013).

\section{Gugus fungsional selulosa dan selulosa asetat sabut kelapa sawit}

Spektroskopi FTIR digunakan dalam mengidentifikasi senyawa, khususnya senyawa organik baik secara kualitatif maupun kuantitatif. Informasi yang diberikan berdasarkan bilangan gelombang dalam menentukan gugus fungsional dalam molekul organik.

Tabel 1 Perbandingan bilangan gelombang hasil spektrum FTIR selulosa

\begin{tabular}{cccc}
\hline $\begin{array}{c}\text { Selulosa } \\
\text { Komersil } \\
\left(\mathbf{c m}^{-1}\right)\end{array}$ & $\begin{array}{c}\text { Selulosa } \\
\text { Sabut } \\
\text { Kelapa } \\
\text { Sawit } \\
\left.\mathbf{( c m}^{-1}\right)\end{array}$ & $\begin{array}{c}\text { Daerah } \\
\text { bilangan } \\
\text { gelomban } \\
\mathbf{g}\left(\mathbf{c m}^{-1}\right)\end{array}$ & $\begin{array}{c}\text { Nama } \\
\text { gugus } \\
\text { fungsi }\end{array}$ \\
\hline 3348,42 & 3425,58 & $3750-3000$ & $\mathrm{O}-\mathrm{H}$ \\
2900,94 & 2922,16 & $3000-2700$ & $-\mathrm{CH}_{2-}$ \\
1673,56 & 1739,79 & $1900-1650$ & $\mathrm{C}=\mathrm{O}$ \\
- & 1514,12 & $1675-1500$ & $>\mathrm{C}=\mathrm{C}<$ \\
1373,32 & 1379,10 & $1475-1300$ & $>\mathrm{CH}-$ \\
\hline
\end{tabular}

${ }^{*}$ Fessenden dan Fessenden (2005)

Identifikasi gugus fungsi selulosa dan selulosa asetat dilakukan dengan menggunakan spektrofotometer infra merah dengan rentang bilangan gelombang 4500-400 $\mathrm{cm}^{-1}$ (Tabel 1). Dari Tabel 1 terlihat puncak karakteristik pada selulosa komersil bilangan gelombang $3348,42 \mathrm{~cm}^{-1}$ dan $3425,58 \mathrm{~cm}^{-1}$ pada selulosa sabut kelapa sawit menunjukkan pada daerah tersebut terdapat gugus $\mathrm{OH}$. Karena pada bilangan gelombang tersebut terdapat ikatan hidrogen yang merupakan gugus utama dari selulosa (Lestari, 2012). Gugus $-\mathrm{CH}_{2^{-}}$terdapat pada daerah frekuensi $3000-2700 \mathrm{~cm}^{-1}$ yang merupakan kerangka pembangun struktur selulosa. Kemudian, pada bilangan gelombang $1673,56 \mathrm{~cm}^{-1}$ pada selulosa komersil dan $1739,79 \mathrm{~cm}^{-1}$ pada selulosa sabut kelapa sawit menunjukkan gugus $\mathrm{C}=\mathrm{O}$ yang merupakan adanya hemiselulosa. Hasil isolasi selulosa dari sabut kelapa sawit terdapat gugus $\mathrm{C}=\mathrm{C}$ pada bilangan gelombang $1514,12 \mathrm{~cm}^{-1}$ menunjukkan adanya senyawa lignin yang masih terkandung. Menurut Zuliahani et al. (2016) adanya senyawa hemiselulosa juga ditunjukkan adanya vibrasi pada bilangan gelombang $1720,50 \mathrm{~cm}^{-1}$ yang mana bilangan gelombang ini merupakan vibrasi ulur gugus asetil atau ester pada senyawa hemiselulosa. Sedangkan, pada selulosa komersil tidak terdapat vibrasi yang menunjukkan adanya senyawa lignin.

Dari Tabel 2 terlihat bahwa pada bilangan gelombang $1749,44 \mathrm{~cm}^{-1}$ pada selulosa asetat dan $1637,56 \mathrm{~cm}^{-1}$ pada selulosa asetat sabut kelapa sawit adanya 
gugus karbonil $(\mathrm{C}=\mathrm{O})$ ester. Gugus $\mathrm{CO}$ asetil juga terdapat dalam senyawa tersebut yakni pada bilangan gelombang $1244,09 \mathrm{~cm}^{-1}$ pada selulosa asetat dan $1163,08 \mathrm{~cm}^{-1}$. Menurut penelitian yang dilakukan oleh Lismeri et al. (2016) Gugus karbonil $(\mathrm{C}=\mathrm{O})$ selulosa asetat serat batang ubi kayu terdapat pada daerah bilangan gelombang 1738,47 $\mathrm{cm}^{-1}$, sedangkan pada selulosa asetat komersial terletak pada bilangan gelombang $1744,87 \mathrm{~cm}^{-1}$.

Tabel 2 Perbandingan bilangan gelombang hasil spektrum FTIR selulosa asetat

\begin{tabular}{|c|c|c|c|}
\hline $\begin{array}{c}\text { Selulosa } \\
\text { Asetat } \\
\text { komersil } \\
\left(\mathrm{cm}^{-1}\right)\end{array}$ & $\begin{array}{c}\text { Selulosa } \\
\text { Asetat } \\
\text { Sabut } \\
\text { Kelapa } \\
\text { Sawit } \\
\left(\mathrm{cm}^{-1}\right)\end{array}$ & $\begin{array}{c}\text { Bilangan } \\
\text { gelombang } \\
\left(\mathrm{cm}^{-1}\right)\end{array}$ & $\begin{array}{l}\text { Nama } \\
\text { gugus } \\
\text { fungsi }\end{array}$ \\
\hline 3414,00 & 3425,58 & $3750-3000$ & $\mathrm{O}-\mathrm{H}$ \\
\hline 2897,08 & 2922,16 & $3000-2700$ & $-\mathrm{CH}_{2-}^{-}$ \\
\hline 1749,44 & 1637,56 & $1900-1650$ & $\begin{array}{l}\mathrm{C}=\mathrm{O} \\
\text { ester }\end{array}$ \\
\hline 1377,17 & 1379,10 & $1475-1300$ & $>\mathrm{CH}-$ \\
\hline 1244,09 & 1163,08 & $1250-1000$ & $\begin{array}{l}\text {-CO- } \\
\text { asetil }\end{array}$ \\
\hline
\end{tabular}

${ }^{\star}$ Fessenden dan Fessenden (2005)

Gugus ester C-O selulosa asetat serat batang ubi kayu terdapat pada daerah bilangan gelombang $1224,39 \mathrm{~cm}^{-1}$, sedangkan pada selulosa asetat komersial terletak pada bilangan gelombang $1232,72 \mathrm{~cm}^{-1}$. Kedua gugus tersebut merupakan puncak serapan yang dimiliki senyawa selulosa asetat (Widyaningsih dan Radiman, 2007).

\section{Adsorpsi Logam Pada Pelumas Bekas}

Perbandingan rasio antara selulosa asetat dan kitosan yang paling baik ialah
3:1 dengan $\mathrm{pH} 5$ yang memiliki daya serap sebesar 100 \% (Gambar 1). Hajrah et al. (2018) melaporkan bahwa kadar timbal yang terserap oleh arang aktif biji kelor sebesar 86,31\% dengan waktu kontak 3 jam.

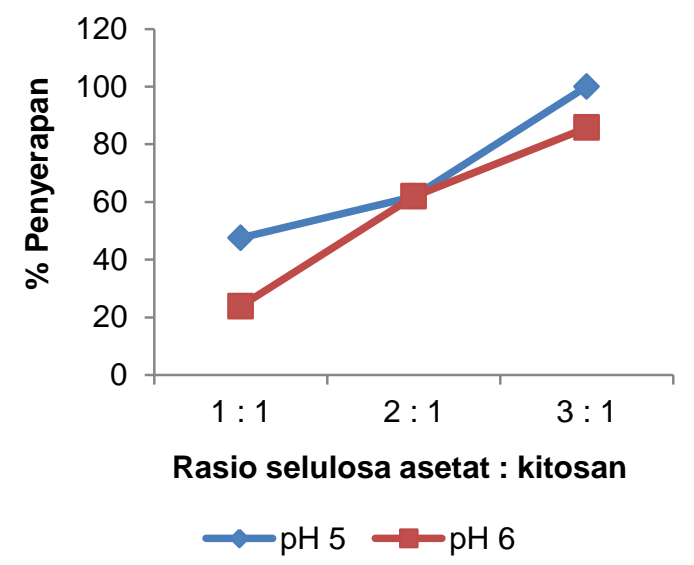

Gambar 1Grafik Logam Pb yang terserap oleh selulosa asetat-kitosan

Pada penelitian yang dilakukan oleh Pratiwi (2013) efisiensi penurunan kadar $\mathrm{Pb}$ dalam pelumas bekas menggunakan metode acid clay treatment $\mathrm{pH} \quad 4,4$ sebesar $56,71 \%$. Rasio selulosa asetat dan kitosan semakin meningkat jumlah selulosa setat maka semakin besar pula penyerapan logam tembaga (Gambar 2). Seperti penelitian yang dilakukan oleh Thaiyibah., et al. (2016) mengatakan bahwa semakin banyak jumlah selulosa asetat maka semakin banyak gugus yang memiliki atom yang menjerap logam. Sehingga akan meningkatkan jumlah $\mathrm{Cu}^{2+}$ yang terikat karena meningkatnya derajat polarisasi akibat pencampuran. Sedangkan, apabila jumlah selulosa setat terlalu sedikit maka proses mobilitas ion antar muka akan terhambat oelh kapasitas 
tukar ion yang menurut, akibatnya logam $\mathrm{Cu}^{2+}$ yang terjerap lebih sedikit.

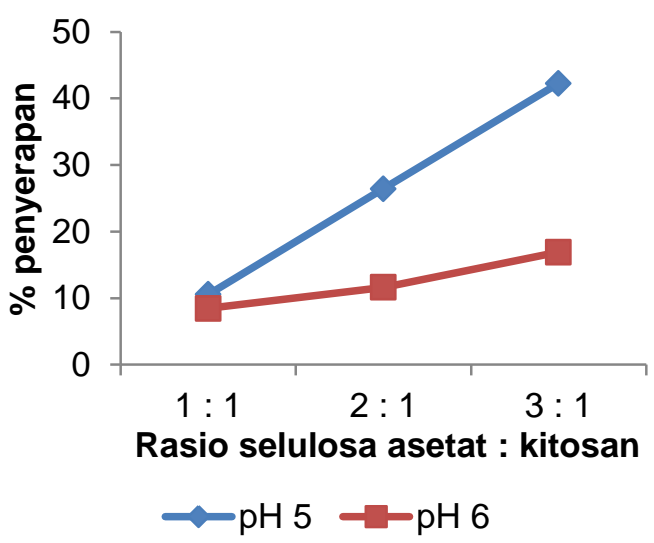

Gambar 2 Grafik Logam Cu yang terserap oleh selulosa asetat-kitosan

Rasio pencampuran selulosa asetat dan kitosan yang baik ialah 3:1 pada $\mathrm{pH} 5$ dengan kadar tembaga yang terserap sebesar $42,27 \%$. Berbeda dengan hasil penelitian yang dilakukan oleh Nindya dan Taty (2018) kadar tembaga pada oli bekas yang terserap sebesar $0,542 \mathrm{mg} / \mathrm{L}$ atau setara dengan 90,68\% menggunakan adsorben campuran semen dan bentonit dengan perbandingan 50:50. Pada penelitian yang dilakukan oleh Thaiyibah et al. (2016) dari hasil analisis FTIR terdapat interaksi antar ion $\mathrm{Cu}^{2+}$ dengan membran dengan adanya penurunan intensitas serapan sebelum dan sesudah didop yaitu $78.564 \%$ menjadi $66.857 \%$ pada gugus $\mathrm{C}=\mathrm{O}$ dari selulosa asetat. Membran yang digunakan ialah campuran selulosa asetat, PVC dan DOP dengan perbandingan berturut- turut yakni 6:3:1.

\section{KESIMPULAN}

Berdasarkan hasil penelitian dapat disimpulkan bahwa rasio terbaik campuran selulosa asetat sabut kelapa sawit dan kitosan untuk adsorpsi logam $\mathrm{Pb}$ dan $\mathrm{Cu}$ dari pelumas bekas adalah rasio 3:1. $\mathrm{pH}$ terbaik campuran selulosa asetat sabut kelapa sawit dan kitosan untuk adsorpsi logam $\mathrm{Pb}$ dan $\mathrm{Cu}$ dari pelumas bekas adalah $\mathrm{pH} 5$ dengan serap masing masing $100 \%$ dan $42,27 \%$.

\section{DAFTAR PUSTAKA}

Abdel-Jabbar,N.M., Essam A.H. Al Zubaidy, dan Mehrvar, M. 2010. Waste Lubricating Oil Treatment by Adsorption Process Using Different Adsorbents. International Journal of Chemical and Biological Engineering 3:2

Apriana, D., Rahih E A., Ruslan. 2018. Pembuatan Membran Selulosa Asetat dari Selulosa Pelepah pohon Pisang. KOVALEN, 4(1): 41-52.

Azteria, V., dan Efendi, J. 2017. Identifikasi Keselamatan Penanganan Limbah Pelumas Pada Pt.Altrak 1978 Balikpapan. Jurnal Biologi Lingkungan, Industri, Kesehatan, 4(1).

Bahmid, N.A., Syamsu, K., \& Maddu, A. 2013. Production of cellulose acetate from oil palm empty fruit bunches cellulose. Chemical and Process Engineering Research, 17: 12-20.

Baroroh, A., Anita, D. M., Ellyke. 2016 Pemanfaatan Serbuk Selulosa Kulit Kakao sebagai Adsorben Logam Berat $\mathrm{Ni}$ pada Limbah Cair Elektroplating. (diunduh di http://repository.unej.ac.id/handle/12 3456789/79118, diakses pada tanggal 30 Mei 2018).

Dahlan, M. H., Setiawan, A., dan Rosyada, A. 2014. Pemisahan Oli 
Bekas dengan Menggunakan Kolom Filtrasi dan Membran Keramik Berbahan Baku Zeolit dan Lempung. Teknik Kimia, 1(20): 38-45.

Ferdiansyah, M. K., Marseno, D. W., Panoto, Y. 2015. Sintesis Karboksi Metil Selulosa (CMC) dari Pelepah Kelapa Sawit Menggunakan Response Surface Methodology (RSM). agriTECH, 37(2): 158-164

Fessenden, R.J. dan Fessenden, J.S. 2005. Kimia Organik. In Pudjaatmaka, A.H. (ed.). Jakarta: Erlangga.

Hajrah., Ruslan., Prismawiryanti. 2018. Pemanfaatan karbon aktif biji kelor (Moringa Oleifera) sebagai penyerap logam timbal dalam oli bekas. KOVALEN, 4(3): 297-303.

Hasyim, U. H. 2016. Review: Kajian Adsorbsi Logam Dalam Pelumas Bekas Dan Prospek Pemanfaatannya Sebagai Bahan Bakar. KONVERSI, 5(1): 11-16.

Israel, A.U., Obot, I.B., \& Asuquo, J.E. 2008. Production of cellulosic polymers from agricultural wastes 85 $35.70, \quad 52.00$ and $38.70 \%$ respectively. E-Journal of Chemistry, 5(1): 81-85.

Jodeh, S., Odeh R., Sawalha M., Obeid, A.A., Salghi R., Hammouti B., Radi S., Warad, I. 2015. Adsorption of Lead and Zinc from Used Lubricant Oil Using Agricultural Soil: Equilibrium, Kinetic and Thermodynamic Studies. J. Mater. Environ. Sci., 6 (2).

Kusumah, A. M. 2013. Perolehan Kembali Bahan Dasar Pelumas dari Limbah Pelumas Mesin dengan Metode Adsorpsi dan Penciriannya. Skripsi. Bogor: FMIPA IPB.
Lestari, M.D., Sudarmin dan Harjono. 2014. Ekstraksi Selulosa dari Limbah Agar menggunakan Larutan $\mathrm{NaOh}$ sebagai prekursor Bioetanol. Indonesian Journal of Chemical Science, 7(3).

Lianna, J., karyati, Y., dan Santosa, H. 2012. Penjernihan Minyak Pelumas Bekas dengan Metode Penjerapan Suatu Usaha Pemanfaatan kembali Minyak Pelumas Bekas sebagai Base Oil. Jurnal Teknologi Kimia Industri, 1(1): 252-257.

Lismeri, Lia., Poppy M.Z., Tika N., Yuli D. 2016. Sintesis selulosa asetat dari limbah batang ubi kayu. Jurnal Rekayasa Kimia dan Lingkungan, . 11(2): 82-91.

Liu, H. 2007. Effect of Ultrasonic Treatment on The Biochemphysical Properties of Chitosan. Carbohydrate Polymers, 64(4):553559.

Muckti, P. H. 2012. Daur Ulang Minyak Pelumas Bekas Menjadi Minyak Pelumas Dasar Dengan Kombinasi Batubara dan Karbon Aktif. Skripsi. Jawa Timur: Universitas Pembangunan Nasional Veteran.

Muthia, F. 1998. Pembuatan Arang Aktif dari Sabut Kelapa Sawit Sebagai Bahan Penjernihan Air. Skripsi. Bogor: Fakultas Pertanian Bogor.

Nindya Puspa, A. dan Taty, A. 2018. Penurunan Kadar Cu dalam Proses Solidifikasi Limbah Oli Bekas 15\% menggunakan semen Portlan dan Bentonit. Prosiding Seminar Nasional Sains dan Teknologi Terapan. Surabaya: Institut Teknologi Adhitama Surabaya.

Permanasari, A., Siswaningsih, W., Wulandari, I. 2010. Uji Kinerja Adsorben Kitosan-Bentonit Terhadap Logam Berat dan 
Diazinon Secara Simultan. Jurnal Sains dan Teknologi Kimia, 1(2): 121-134.

Pratiwi, Y. 2013. Pengolahan Minyak Pelumas Bekas Menggunakan Metode Acid Clay Treatment. Jurnal Teknik Sipil UNTAN, 13(1): 1-12.

Rahmawati, Ani. 2006. Pemanfaatan Limbah Kulit Ubi Kayu (Manihot utilissima Pohl.) pada Produksi Bioetanol Menggunakan Aspergillus niger. Skripsi. Semarang: Jurusan Biologi FMIPA Universitas Sebelas Maret.

Roberts, G. A . F. 1992. Chitin Cemistry. London: The Macmilan Press LTD.

Thaiyibah, N., Alimuddin., Panggabean A. S. 2016. Pembuatan Dan Karakterisasi Membran Selulosa Asetat-PVC Dari Eceng Gondok (Eichhornia Crassipes) Untuk Adsorpsi Logam Tembaga (II). Jurnal Kimia Mulawarman, 14: 29-35

Widyaningsih, D. dan Radiman, C.L. 2007. Pembuatan Selulosa dari Pulp Kenaf (Hibiscus Cannabius). Molekul, 2(1): 13-16.

Zuliahani Ahmad, Nurul Nadhirah Roziaizan, Rozyanty Rahman, Ahmad Faiza Mohamad, and Wan Izhan Nawawi Wan Ismail. 2016. Isolation and Characterization of Microcrystalline Cellulose (MCC) from Rice Husk. MATEC Web of Conferences, vol. 47. The 3rd International Conference on Civil and Environmental Engineering for Sustainability (IConCEES 2015).

Souhoka, F. A. 2013. Metilasi Green Selulosa menggunakan Dimetil Karbonat (DMC) dengan menggunakan Teknik Sonokimia dan Gelombang Mikro. Tesis. Yogyakarta: Jurusan Kimia FMIPA. UGM. 